\title{
Evaluation of the Mental Skills of the High Level Athletes: Example of the Athletes of Martial Arts
}

\author{
Fairouz Azaiez ${ }^{1,2}$, Nasr Chalghaf ${ }^{1,2}$, Ebdelhakim Cherif ${ }^{1,2}$, Karim Achour $^{1}$, \\ Chohdi Souissi ${ }^{1}$ \\ 1- Higher institute of Sport and the Physical Education of Sfax (Tunisia) \\ 2- StudiesGroup of Development and Social Environment (Faculty of Social Sciences and Lettersof Sfax)
}

\begin{abstract}
The domain of sport competition is developing every day so the athletes nearly have the same physical abilities and have different mental skills. Therefore, it is not possible to ignore the role of mental skills to achieve maximum performance, Heever (2007). Most sport psychologists believed that in recent years the coaches and athletes have concluded that they need psychological skills more than physical skills in order to achieve their goals, Behboudi (2007).

The purpose of the present study was to compare some psychological skills of the martial arts high level athletes (judokas, boxers, wrestlers and karate as) in Tunisia. 152 volunteer athletes of martial sports (95 Judokas, 15 Wrestlers, 12 Boxers and 30 karate as) including 89 men and 63 women answered the Ottawa Mental Skills Assessment Tools (version 4). This questionnaire assessed three categories of mental skills: fundamental skills, psycho-somatic skills and cognitive skills. The results revealed mean differences for all the mental skills between the different activities in the benefit of judokas but this differences was not significant. Despite this difference in averages, the analysis of the 12 mental skills by gender is significant only for the control of fear (significant atp $<0.05$.
\end{abstract}

Key Words:Omsat- 4, Mental skills, Martial arts.

\section{Introduction}

In the martial arts withenergetic dominance, the work of the trainers and athletes are in general directed more towards the development of physical and technical qualities. Indeed,the VO2max or the anaerobic threshold isgood predictors of the judoka performance (Molina, \&Villamon, 1998). With technical potontials equalities, it is the adversary who have the best physical condition will vanquish. How you practice boxing, judo or wrestling, without a very good physical preparation is impossible to climb the levels which will lead you to the victory(Bouchard, Brunelle, \& Godbout, 1973; Sacripanti, 1989; Ama, Simoneau, Boulay, Seresse, Thériault\& Bouchard, 1986). The fighting is before any emotion, because it integrates strong emotional dimensions such as fear, pleasure, distress, confidence, perception of the risk and safeguarding of its safety. The martial arts are as many contradictory interfaces to consider (Therme, 2006). The share of mental appears thus paramount to hold these long efforts: intern dialogue, fixing of targets, capacity to mobilize all its energy «When one has badly, it is initially often the head which says stop (Leveque, 2012). It is necessary to knowhow to exceed the suffering, not to crack and go possible further. Arripe-Longueville, Baker \& Dubois (1998).

The psychological aspect is now regarded as being one of the factors contributing to the production of performance (Cox, 2005; Target, 2003, 2006; Mahoney, Gabriel \&Perkins, 1987; Orlick, 2008; Leveque, 2008, 2010; Ripoll, 2008). However, in Tunisia, the activities of accompaniment of the athletes, research and training are clearly stated, neither by the federations nor by the institutions.

The mental skills are defined like processes or techniques making it possible to control or direct the thoughts, the strategies, the feelings and the emotions essential to the performance (Smith, 2003); Thomas, Murphy \& Hardy, 1999; Gould, 2001). The application of techniques to develop and work the mental skills develops more and more among sporting candidates and proves to be effective (Thad, Leffingwell, Rider \& Williams, 2001; Tremblay, Welsh \& Elliott. 2001). More particularly, it was shown that the mental skills such as the capacity in activation, with the listening of its body, relieving, the installation of routines (Gould D; Udry E, 1994), with the fixing of goal, the mental imagery, the management of the stress or with the intern dialogue (White\& Hardy, 1995; Meyers, Whelan \& Murphy, 1996; Roure, Collet, Deschaumes-Molinaro, Delhomme, Dittmar\&Vernet-Maury, 1999) are known like facilitators of the performance. Also, another study (Neil, Mellalieu\&Hanton, 2004, 2006; Mellalieu, Neil\&Hanton, 2006; Mellalieu, Hanton\& O' Brien, 2004) noted that the use of the mental skills could have an impact on the competitive anxiety management. Several researchers who work on the effect of the mental drive program to identify the favorable effects in different sports (Cogan \& Petrie, 1995; Orlick\&Partington, 1986, 1987; Savoy, 1993). 
An athlete can profit from a program of mental preparation having favorable effects in particular on his performance (Kendall, Hrycaiko, Martin, \& Kendall, 1990; Li-Wei, IQ-Wei, Orlick\&Zitzelsberger, 1992), and on specific psychological resources such as confidence (Bakker \&Kayser, 1994; Baker, Horton, Pearce, \&Deakin, 2005; Maallett\&Hanrahan, 2004) or imagery skill (Rodriguez, Wigfield\&Eccles, 2003).Many studies showed the benefit of a work besides on the mental skills for the sports of endurance such as the triathlon (Thelwell, Such, Weston, Such\&Greenlees, 2010; Thelwell, Greenlees\& Weston, 2006). Another proposed that a good internal dialogue can allow an athlete of a discipline of endurance and force, to exceed its suffering during its race and to increase its performance (Cogan \& Petrie, 1995; Theodorakis, Weinberg,Natis, Douma\&Kazakas, 2000) also showed the favorable influence of this kind of intervention on the competitive anxiety and individual cohesion.

On this subject, the study of Baker Side Hawes, (2000) showed that negative relationship between the trainer and the athletes acted significantly on all shapes of anxiety of the athletes (somatic, cognitive, lack of concentration, concern). Moreover, the capacity of the coach gave or not strategies of competition adapted to the athletes, could also influence these forms of anxiety (Eys, Hardy, Carron \& Beauchamp, 2003). The anxiety can involve an unexpected answer. It occurs because the individual fears a future situation. Buceta (1985) found lines hot to help the athlete for his way of judging itself, to accept the facts, to discuss the negative reinforcements which influence the level of anxiety considerably. Concerns cause a stress caused by the fear of the situation for Gray $(1990,2002)$, the anxiety is an emotional state fundamental, directed towards a goal and synonymous with the fear.

Lastly, more recently, Calmels, Arripe-Longueville, Baker \&Soulard (2003), highlighted the use of strategies more diversified and worked out at gymnasts of national level having profited from a mental drive, thangymnasts of the same level without mental drive. This study suggests the utility of the teaching of the mental skills, in high level gymnastics, by the means of a program of mental drive. It invites in addition to better identifying the «natural " methods of development of the psychological resources of the high level gymnasts (Fournier, Calmels, Durand-Bush\&Salmela (2005); Calmels\& Fournier (2001) underlined, at female gymnasts of national level, the positive effects of a program of mental drive on the competitive performance and the management of a certain number of mental skills, such as the reaction to the stress, relieving, the attentional abilities and the imagery.

Always on the study of the gender and personality of the female athletes showed that those posted a personality very close to the male athlete: insurance, directed towards the achievement, dominant, autonomous, independent, aggressive, intelligent, and reserved. (Freedson, Mihevic, Loucks\&Girandola,1983). Conversely, a study on the climbing ones showed that the difficulty of the competitive task involved much more negative affects in the girls than among boys (Asci, Demirhan, Koca\&Dinc, 2006).

Stevenson (1999) did not indicate any significant difference in mental qualifications selected between the men and the women while the results of the current study showed a significant difference between the men and of the women in the competence of activation in a manner that the men employed this mental competence more than women. Activation is a process in which the individual increases his physiology and mental statute in the situations where a higher energy, the motivation and the concentration are required (Kruger, 2010). One of the possible reasons of the finished women of the superiority of the men by employing this competence could be the fact that the martial sport is more compatible with male characteristics and completely the men are able of activation and this is rooted in the characteristics of sexuality.

In a study by Bernier \& Fournier (2007) on the male athletes of elite and female French of hockey, one observed significant differences in gender for the basic qualifications of the arrangement and the engagement of goal. Thus, the men marked higher in confidence, the reaction of effort, relieving and the illustrated language than the women who marked higher in competition planning.

With regard to the visual-space skills, the boys present a significant and robust superiority that the girls that it is on the level of the visual apprehension of the configuration of the objects, their position and their orientation in a space bi- or three-dimensional (Halpern \&Collaer, 2005; Voyer\&al, 1995) on the level of mental rotation: even in infants, the variation is present (Moore \& Johnson, 2008; Quinn\&Liben, 2008).

Beyond these contradictions of the scientific literature, it appears that on these two groups of athletes, the girls have more difficulty to manage their emotions and that represents a track interesting of work for the trainers.

\section{Method}

The population is made up of 152 volunteer athletes of martial sports (95 Judokas, 15 Wrestlers, 12 Boxers and 30 karatekas) including 89 men and 63 women (mean age $=20.64 \pm 2.60$ ) all belonging to the promotion center in Sfax (Tunisia). The mean age of the men $=21.2 \pm 2.853$ and the mean age of the women $=$ $19.85 \pm 1.958$.

The questionnaire used in this study is (Ottawa Mental Skills Assessment Tool "OMSAT- 4"). It was adapted by Fournier, Bernier, \& Durand-Bush (2007) for French-speaking sportsmen from the English version 
of the OMSAT-3 (Durand-Bush, Salmela, \& Green-Demers, 2001). The OMSAT-4 with 85 Itemsevaluates twelve mental skills classified in the following way:

- Fundamental skills (establishment of goals, self-confidence, engagement)

- Psychosomatic skills (reaction to the stress, controls fear, relieving, activation)

- Cognitive skills (concentration, control of the distractions, imagery, mental practical, planning of the competitions).

The scores of the 12 under-scales are consisted the averages of the self-evaluations of 4 assertions, on aLikert scale with 7 points (of at all of agreement to completely of agreement).

\section{Results}

In order to check the psychometric quality of built, an orthogonal analysis of type Varimax (Kaiser, 1958 ) is carried out on our questionnaire starting from the 85 items (OMSAT-4, Fournier, Bernier, \& DurandBush, 2007).

In order to reduce the contents of the table, the weight of the items, by factor is registered by .40 criteria also retained by Acher and Haigh, (1997).

Thepresented results indicate that the rating scale of the French version (for Tunisia) of questionnaire OMSAT-4 has an excellent internal consistency (Alpha $=\mathbf{. 9 0 3 6}$ and a good temporal stability $(\mathrm{r}=$ test and re-test $=.789)$ (table: 1).

Tab.1-Analysis of reliability using alpha of Cronbach( $\mathrm{N}=152$ athletes $)$.

\begin{tabular}{|c|c|c|c|c|c|}
\hline \multirow[b]{2}{*}{ Mental Skills } & \multicolumn{2}{|c|}{$\begin{array}{l}\text { Value } \alpha \text { for the totality of the } \\
\text { items (Bernier, Fournier \& al, } \\
\text { 2007) }\end{array}$} & \multirow{2}{*}{$\begin{array}{c}\text { Value } \boldsymbol{\alpha} \text { original study } \\
\text { (Durand-Bush, \& al, } \\
\text { 2001) }\end{array}$} & \multicolumn{2}{|c|}{ Value $\boldsymbol{\alpha}$ for our study 2013} \\
\hline & $\begin{array}{l}\text { Value } \boldsymbol{\alpha} \text { for the } \\
\text { totality of the } \\
\text { items }\end{array}$ & $\begin{array}{c}\text { Value } \boldsymbol{\alpha} \text { after } \\
\text { suppression of } \\
\text { one item }\end{array}$ & & $\begin{array}{c}\text { Value } \boldsymbol{\alpha} \text { for the } \\
\text { totality of the } \\
\text { items }\end{array}$ & $\begin{array}{c}\text { Value } \boldsymbol{\alpha} \text { after } \\
\text { suppression of } \\
\text { one item }\end{array}$ \\
\hline Goals setting & .70 & & .74 & .72 & \\
\hline Self confidence & .72 & & .78 & .60 & $.69(12)$ \\
\hline Commitment & .67 & $.68(7)$ & .79 & .81 & \\
\hline Stress reaction & .64 & & .73 & .76 & \\
\hline Fear control & .55 & & .68 & .70 & \\
\hline Relaxation & .82 & & .83 & .78 & \\
\hline Activation & .58 & $.60(37)$ & .79 & .71 & \\
\hline Focusing & .57 & $.58(38)$ & .72 & .77 & \\
\hline Refocusing & .63 & & .81 & .63 & $.74(80)$ et $(81)$ \\
\hline Imagery & .78 & & .88 & .80 & \\
\hline Mental practice & .54 & & .76 & .82 & \\
\hline Competition planning & .59 & & .83 & .74 & \\
\hline Value $\alpha$ for the totality of the items & & & & .90 & \\
\hline
\end{tabular}

The results of the scales of various mental skills aregood in the majority, although some items presents a critical value (.60), such as the under-scale of confidence and control of the distractions.

The results of the exploratory analysis show that the mental skills scale of the athletes reproduces the ideal well model with anexcellentintern consistency $(\alpha=\mathbf{9 0 3 6}$. Theobtained measurements starting from the matrix of correlation between the 12 statements of the mental skills(Goals, confidence, Engagement, reaction to the stress, fearcontrol, Relaxation, Activation, focusing, distractions control, mentalImagery, mental Practice, competitions Planning) (table. 2), indicate that there is a significant correlation with $\mathrm{p}<.01$ between almost all the variables. For example between the reaction to the stress (4) and goalsestablishment ( $\mathrm{r}=.798$ with $\mathrm{p}<.01)$. Also between engagement $(3)$ and the reaction to stress $(4)(r=.755$ with $\mathrm{p}<.01)$. As wellbetween the mental practice (11) and the planning of the competitions $(12)(\mathrm{r}=.704$ with $\mathrm{p}<.01)$.

However, there are some coefficients which are small such as those between the focusing (8) and relaxation(5); the competitions planning(10) $(\mathrm{r}=-.184$ with $\mathrm{p}<.05)$. 
Tab.2 - Analyze in principal components of the mental skills

\begin{tabular}{|c|c|c|c|c|c|c|c|c|c|c|c|}
\hline & 1 & 2 & 3 & 4 & 5 & 6 & 7 & 8 & 9 & 10 & 11 \\
\hline 1. Goals Setting & 1 & & & & & & & & & & \\
\hline 2. Sef Confidence & $.494 * *$ & 1 & & & & & & & & & \\
\hline 3. Commitment & $.597 * *$ & $.488 * *$ & 1 & & & & & & & & \\
\hline 4. Stress reaction & $.798 * *$ & $.597 * *$ & $.755^{* *}$ & 1 & & & & & & & \\
\hline 5. Relaxation & $.489 * *$ & $.278 * *$ & $.497 * *$ & $.501 * *$ & 1 & & & & & & \\
\hline 6. Fear Control & .062 & .028 & -.008 & -.020 & -.044 & 1 & & & & & \\
\hline 7. Activation & $.549 * *$ & $.308 * *$ & $371 * *$ & $.485 * *$ & $.544 * *$ & -.143 & 1 & & & & \\
\hline 8. Focusing & -.112 & -.107 & -.148 & $-.206 *$ & $-.184 *$ & $.329 * *$ & $-.164 *$ & 1 & & & \\
\hline 9. Imagery & $.538 * *$ & $.406^{* *}$ & $.570 * *$ & $.561 * *$ & $.470 * *$ & -.105 & $.459 * *$ & -.143 & 1 & & \\
\hline 10. Competition planning & $.627 * *$ & $.497 * *$ & $.618 * *$ & $.610 * *$ & $.504 * *$ & -.080 & $.606^{* *}$ & $-.184 *$ & $.659 * *$ & 1 & \\
\hline 11. Mental Practrice & $.566 * *$ & $.404 * *$ & $.570 * *$ & $.575 * *$ & $.571 * *$ & -.037 & $.554 * *$ & $-.186^{*}$ & $.546 * *$ & $.704 * *$ & 1 \\
\hline 12. Refocusing & .038 & .077 & .027 & -.011 & -.028 & $.212 * *$ & -.083 & $.328 * *$ & -.051 & -.019 & .025 \\
\hline
\end{tabular}

To test the null hypothesis that the way athletes assess their mental abilities (skills basic, skills psychosomatic and cognitive abilities). The Bartlett test of sphericity, gives us a value of 887,061 at $\mathrm{p}<.001$, which can reject the null hypothesis and accept the alternative hypothesis.

The examination of the individual variables is facilitated by calculating the measures of sampling adequacy of Kaiser-Meyer-Olkin (KMO). This index calculated by the matrix of inter-correlation is excellent (.873).

After the extraction of the eigenvalues, we can say that $58,373 \%$ of the variance of the mental skillsare evaluated by our athletes.

The examination of the matrix of the factorial weights after the Varimax type rotation (table 3)makes it possible to note that the first component is defined by the majority of the mental skills such as the goals establishment (.818), the self-confidence (.632), engagement (.794) which constitutes the fundamental skills. As well as the reaction to the stress (.856). On the other hand the second component, as for it, is defined only by the forms of mental skills which are the control of the fear (.703), the control of the distractions (.702) and finally the concentration (.709).

Tab.3- Components Matrix after orthogonal rotation of Varimaxtype: Variance with standardization of Kaiser of the dimension "mental skills".

\begin{tabular}{|c|c|c|}
\hline & \multicolumn{2}{|c|}{ Fators } \\
\hline & 1 & 2 \\
\hline \multicolumn{3}{|c|}{ Fondation Skills } \\
\hline Goals setting & .818 & \\
\hline Self confidence & .632 & \\
\hline Commitment & .794 & \\
\hline \multicolumn{3}{|c|}{ Psychosomatic Skills } \\
\hline Stress control & .856 & \\
\hline Fear control & .697 & \\
\hline Activation & .702 & \\
\hline Relaxation & & .703 \\
\hline \multicolumn{3}{|c|}{ Cognitive skills } \\
\hline Imagery & .754 & \\
\hline Mental practice & .797 & \\
\hline Competition planning & .847 & \\
\hline Focusing & & .709 \\
\hline Refocusing & & .702 \\
\hline
\end{tabular}

The martial sports athletes use more fundamental skills (mean $=5.708$ ) (table 4 ) in so much mental qualifications such as the fixing of the goals and engagement to achieve what they wish to carry out (mean $=5.86$ vs 5.81$)($ fig.1). The results of this study indicate that these athletes test many 
difficulties of focusing (mean $=3.8$ ) which generates feelings of fear (mean $=4.21)$, disappointments and anxiety (mean $=4.31$ ) (fig. 1 ).

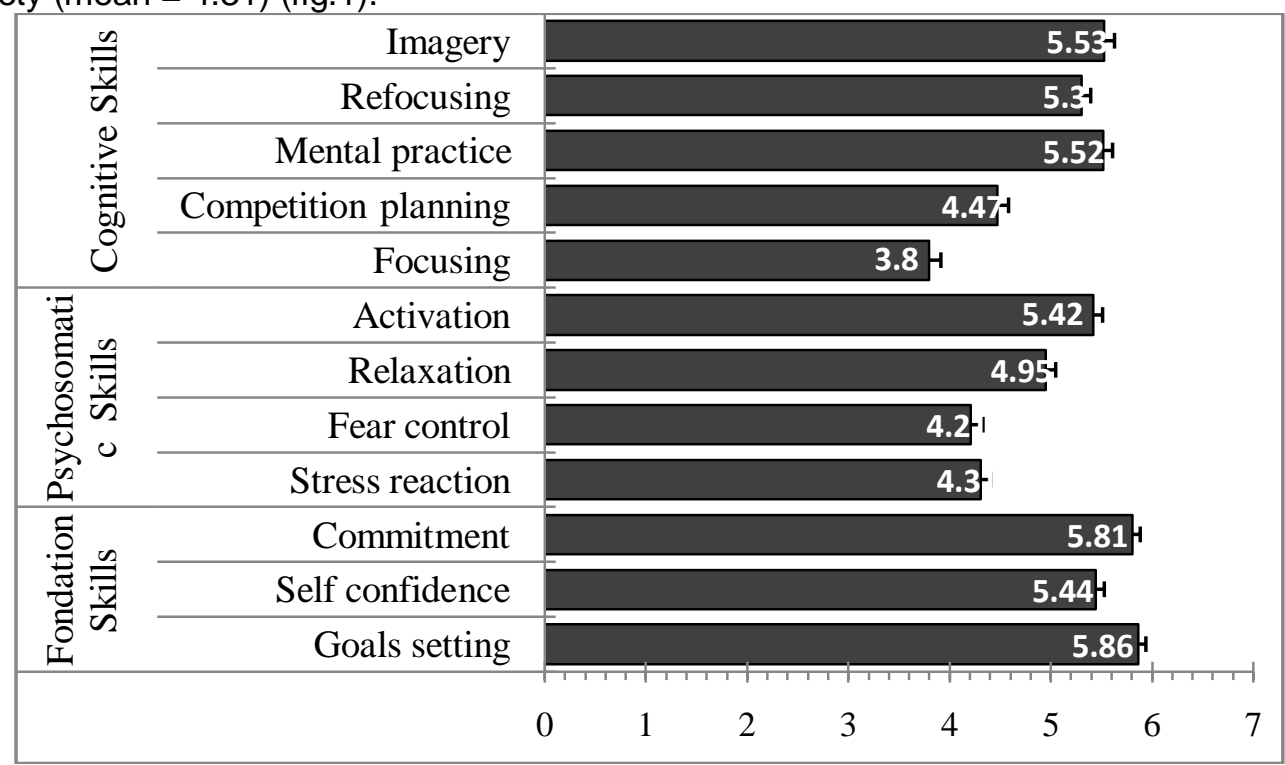

Fig. 1 average Scores of the mental skillsprofile of the martial sportsathletes.

The results of table 4 show a non-significant difference on the twelve mental skills of the OMSAT-4 according to the gender. Knowing that the girls present a higher score than the boys at the level of the goals establishment to achieve whatthey wish to make or to achieve (mean $=5.95 ; \mathrm{Sd}=0.777$ vs mean $=5.77 ; \mathrm{Sd}=$ 1.079). To carry out their objectives, the boys and the girls engage more and more to become remarkable and give $100 \%$ of themselves (boys mean equal to $5.81 ; \mathrm{Sd}=1.165$ vs mean $=5.80 ; \mathrm{Sd}=0.758$ ).

The focusingpresents a problem for the athletes of the martial sports, especially for the girls. They have difficulty to maintain their attentions to carry out a task or a performance $($ mean $=3.66$; $\mathrm{Sd}=1.430$ vs mean $=$ 3.94; $\mathrm{Sd}=1.233$ ).

Tab.4 - Descriptive statistics and gender comparison of the mental skills atmartial sports

\begin{tabular}{|c|c|c|c|c|c|c|c|c|}
\hline & \multirow{2}{*}{\multicolumn{6}{|c|}{ Females $n=63$}} & \multirow{3}{*}{$\mathrm{F}$} & \multirow{3}{*}{ Sig. } \\
\hline & & & & & & & & \\
\hline & Mean & SD & error & Mean & SD & error & & \\
\hline Goals setting & 5,77 & 1,079 & 0,114 & 5,95 & 0,777 & 0,097 & 1,296 & 0,257 \\
\hline Self confidence & 5,53 & 1,019 & 0,108 & 5,34 & 1,165 & 0,146 & 1,187 & 0,278 \\
\hline Commitment & 5,81 & 1,165 & 0,94 & 5,8 & 0,907 & 0,114 & 0 & 0,988 \\
\hline Fondation Skills & 5,708 & 0,758 & 0,08 & 5,703 & 0,758 & 0,095 & 0,002 & 0,968 \\
\hline Stress control & 4,23 & 1,149 & 0,121 & 4,38 & 1,207 & 0,152 & 0,65 & 0,421 \\
\hline Fear control & 4,06 & 1,507 & 0,174 & 4,41 & 1,385 & 0,174 & 2,664 & 0,105 \\
\hline Relaxation & 4,98 & 1,84 & 0,123 & 4,91 & 1,233 & 0,155 & 0,122 & 0,727 \\
\hline Activation & 5,46 & 1,11 & 0,117 & 5,38 & 1,146 & 0,144 & 0,167 & 0,983 \\
\hline Psychosomatic Skills & 4,674 & 0,62 & 0,065 & 4,774 & 0,754 & 0,095 & 0,81 & 0,37 \\
\hline Focusing & 3,66 & 1,43 & 0,152 & 3,94 & 1,338 & 0,168 & 1,466 & 0,228 \\
\hline Refocusing & 5,33 & 1,146 & 0,121 & 5,26 & 1,163 & 0,146 & 0,77 & 0,382 \\
\hline Imagery & 5,64 & 1,204 & 0,127 & 5,41 & 1,233 & 0,155 & 0,134 & 0,715 \\
\hline Mental practice & 5,62 & 0,97 & 0,102 & 5,41 & 1,266 & 0,159 & 1,385 & 0,241 \\
\hline Competition planning & 4,36 & 1,48 & 0,156 & 4,46 & 1,224 & 0,102 & 0,77 & 0,382 \\
\hline Cognitive skills & 4,927 & 0,594 & 0,063 & 7,92 & 0,769 & 0,096 & 0,044 & 0,95 \\
\hline
\end{tabular}

\section{Discussion}

The presented results indicate that the rating scale of the French version (for Tunisia) of the OMSAT-4 questionnaire has an excellent internal consistency (Alpha $=\mathbf{. 9 0 3 6}$ and a good temporal stability $(\mathrm{R}=$ test and Re-test $=.789)$ contrary to the results found by Fournier \& Al, 2008.

Indeed, the athletes perceptions of their capacity to be psychologically prepared for the total group have an essential importance. This confirms the studies of Reilly (1996); Cox (2005), Target (2003); Mahoney, Gabriel \&Perkins (1987); Orlick (2008); Levêque (2008, 2010) and of Ripoll (2008). They note that a growing 
number of athletes give more importance to the psychological preparation. The martial sports athletes use the basic skills (goal establishment, confidence and engagement) as significant mental qualifications. Which in certain measurement,agree with the results of Bakker \&Kayser, (1994); Baker, Horton, Pearce \&Deakin, (2005) and finally of Mallett\&Hanrahan (2004) The results of this study also indicate that the martial sports athletes have many difficulties to find effective strategies to maintain their focusingwithin training and competitions. These results are in an accordance of the studies of Buceta (1985); Baker, Side, Hawes, (2000) and of Eys, Hardy, Carron, Beauchamp (2003). Thatgenerates to them a feeling of fear, stress and anxiety,when they lose their control after being angry or being frustrated.

In connection with the study of the gender on the use of the mental skills of the athletes,we note that there is no significant difference on the twelve psychological skills of the OMSAT-4 according to thegender . Stevenson (1999) goes in the direction of our results by indicating that there is no significant difference in mental qualifications selected between the men and the women. Another study comes supported our results, showed that the women athletes posted a personality very close to the male athlete (insurance, orientation, prevalence, autonomy, cleverness etc.), (Freedson, Mihevic\&Girandola, 1983). Conversely, to the study of Bernier and Fournier (2007) on theelite male and female French hockey athletes showed a significant difference in gender for the basic qualifications. As well as thestudies of Halpern \&Collaer, 2005; Voyer\& Al, 1995 on the Visio-space skills, the boys present a significant superiority than the girls. Also in infants, the gap is present (Moore \& Johnson, 2008; Quinn \&Liben, 2008). Another study on the climbing ones showed that the difficulty of the competitive task involved much more negative effectson the girls than among boys (Asci, Demirhan, Koca\&Dinc, 2006).

\section{Conclusion}

The objective of this study is, firstly to determine the opinions of the athletes of martial sports (judo, wrestling, box and karate) concerning the OMSAT-4 and the need for such programs for the total group and per gender.Secondly, to identify the athlete'sperception of their capacities to be psychologically prepared for competitions.

Moreover, the results proved that the martial sports athletes perceived OMSAT-4 like significant component to increase the performance. The majority of athletes were of the opinion that their ability to mentally prepare for competition was important.

It was also shown that the martial sports players perceived a little non-significant differencebetween the 12 mental skills of the boys and the girls during training and competition. In fighting sports, it appears that the athletes have difficulties of focusing and the use the mental practice.

Infact, these players do not think of being very able to manage their fears, their emotions and their stress to carry out a task or a performance. However, the results show that the martial sports athletes think about setting up goals in training and competition. So they do not judge to have too many negative thoughts in competition and which they would be able to be committed operating its goals. That could be interesting on behalf of the trainers to help their athletes to develop their mental skills, because as we showed in this study, the mental skills in the fighting sports are of a primary importance with the performance. This is why the trainers must devote time necessary to acquire these fundamentals and thus to bring a minimum of the mental training totheir athletes (Gould, Damarjian\&Medberry, 1999). This study would thus bring a new lighting in the direction where it would seem that the lack of the trainers qualification would not prevent them from determining the mental skills of their athletes, on the other hand that would pose indeed problems as for their development.

\section{References}

[1]. A. Kruger, (2010). Sport psychological skills that discriminate between successful and less success full female university field hockey players. African Journal for Physical, Health Education, Recreation and Dance, 16(2).

[2]. A. White\& L. Hardy, (1995). Use of different imagery perspectives on the learning and performance of different motor skills. British Journal of Psychology, 86, 169-180.

[3]. A. Sacripanti, (1989). Biomeccanica del judo, Roma: ed. Mediterranean.

[4]. A.W.Meyers, J.P. Whelan\& S.M. Murphy, (1996). Cognitive behavioral strategies in athletic performance enhancement, ProgBehavModif., 30, 137-64.

[5]. C. Bouchard, J. Brunelle\& P. Godbout, (1973). La préparation d'un champion, Québec: Pélican. Cox, R. H, (2005), Psychologie du sport, Editions de Boeck.

[6]. C.Calmels, F. Arripe-Longueville, J. F. Fournier\& A. Soulard, (2003).Competitive strategies among elite female gymnasts: An exploration of the relative influence of psychological skills training and natural learning experiences. International Journal of Sport and Exercise Psychology, 1, p. 327-352.

[7]. C. Calmels\&J. F. Fournier, (2001).Duration of physical and mental execution of gymnastic routines, The Sport Psychologist, Vol. 15 (2) Jun 2001, 142-150.

[8]. C.J. Mallett\&S.J. Hanrahan,(2004). Elite athletes: why does the 'fire' burn so brightly? Psychology of Sport and Exercise 5 (2004) $183-200$.

[9]. C. Savoy, (1993). Ayearlong mental training program for a college basketball player. The Sport Psychologist, 7, 173-190.

[10]. C. Target, (2003). Manuel de préparation mentale, édition Chiron. 
[11]. D. F. Halpern\& M. L. Collaer, (2005). Sex differences in visuospatial abilities: More than meets the eye. In P. Shah \& A. Miyake (Eds.): The Cambridge handbook of visuospatial thinking (pp. 170-212). New York: Cambridge University Press.

[12]. D. Gould, (2001).The psychology of Olympic excellence and its development, International Society of Sport Psychology Conference, Skiatos, Greece.

[13]. D. Gould\&Udry, E, (1994). Psychological skills for enhancing performance: arousal regulation strategies. Med Sci Sports Exerc, 26(4), 478-85.

[14]. D.J. Smith, (2003). A framework for understanding the training process leading to elite performance, Sports Med., 33(15), $1103-26$.

[15]. D. Rodriguez, A. Wigfield\& J. Eccles, (2003).Changing competence perceptions, changing values: Implications for youth sport: Journal of Applied Sport Psychology, Vol 15(1) Mar 2003, 67-81.

[16]. D.S. Moore\& S.P. Johnson, (2008). Mental rotation in human infants. Psychological Science, 19, $1063-1066$.

[17]. D.Voyer, S.D., Voyer\& M.P. Bryden, (1995). Magnitude of sex differences in spatial abilities: A metaanalysis and consideration of critical variables. Psychological Bulletin, 117, 250-270.

[18]. F. Arripe-Longueville, J. F. Fournier\& A. Dubois. (1998). The perceived effectiveness of interactions between expert French judo coaches and female elite athletes. The Sport Psychologist, 12, 318-333.

[19]. F. H. Asci, G. Demirhan, C. Koca\& S. C. Dinc. (2006). Precompetitive anxiety and affective state of climbers in indoor climbing competition, Percept Mot Skills, 102(2), 395-404.

[20]. F. C. Bakker\& C. S. Kayser, (1994). Effect of a self-help mental training programs,International Journal of Sport Psychology, Vol 25(2) Apr-Jun 1994, 158-175.

[21]. G. Kendall, D. Hrycaiko, G.L. Martin\& T. Kendall, (1990). The effects of an imagery rehearsal, relaxation, and self-talk package on basketball game performance, Journal of Sport \& Exercise Psychology (JSEP), 12(2), 157-166.

[22]. H. F. Kaiser, (1958). The varimax criterion for analytic rotation in factor analysis, Psychometrika 23:187-200

[23]. H. Ripoll, (2008). Le mental des champions, éditions Payot, Paris.

[24]. J. M. Buceta, (1985).Some guidelines for the prevention of excessive stress in athletes. International Journal of Sport Psychology, $16,46-58$.

[25]. J. A. Gray, (1990). Brain systems that mediate both emotion and cognition, Cognition and Emotion, 4(3), 269-288.

[26]. J. A. Gray, (2002). Implications of synaesthesia for functionalism: theory and experiments, Journal of Consciousness Studies, 9 (12), 5-31.

[27]. J. Baker, S. Horton, W. Pearce\& J. M. Deakin, (2005). A longitudinal examination of performance decline in champion golfers: High Ability Studies Vol 16(2) Dec 2005, 179-185.

[28]. J. Baker, J. Côté\&R. Hawes. (2000).The relationship between coaching behaviours and sport anxiety in athletes, J Sci Med Sport, Jun 2000, 3(2):110-9.

[29]. J. Fournier, C. Calmels, N. Durand-Bush\& J. H. Salmela, (2005), Effect of a season-long PST Program on gymnastic performance and on psychological skill development. ISJEP, 1: 7-25.

[30]. J. Archerv\& A.M.Haigh, (1997), Beliefs about aggression among male and female prisoners. AggressiveBehavior, 23, 405-415.

[31]. J.P.Molina\& M.Villamon, (1998). Principes stratégico-tactiques des sports de combat, Revue EPS: recherche et formation, recherche en sport de combat et arts martiaux, 175-184.

[32]. K.D. Cogan\& T. A. Petrie, (1995), Sport consultation: An evaluation of a season-long intervention with female collegiate gymnasts. Sport Psychol., 9: 282-286.

[33]. K.D. Cogan\& T. A. Petrie, (1995). Sport consultation: An evaluation of a season-long intervention with female collegiate gymnasts, Sport Psychol., 1995,9:282-286.

[34]. L.Tremblay, T.N.Welsh\& D. Elliott, (2001). Specificity versus variability: effects of practice conditions on the use of afferent information for manual aiming. Motor Control, 5, 347-360.

[35]. M. A. Eys, J. Hardy, A. V. Carron\&M.R. Beauchamp, (2003). The relationship between task cohesion and competitive state anxiety, J Sport Exercise Psychol., 25:66-76.

[36]. M. Behboudi, (2007).The study of psychological professional karate athletes in world competition, 1st international Islamic world science and sport conference, 43.

[37]. M. Bernier\& J. Fournier, (2007).Mental skill evaluation of French elite athletes. In Y. Theodorakis, M., Gourdas\&Papaionnou (Eds.). Sport and exercise psychology bridges between disciplines and cultures. TheSaloniki: University of Thesaly, pp. 89-91.

[38]. M.J.Mahoney, T.J. Gabriel\& T.S. Perkins, (1987). Psychological skills and exceptional athletic, performance, The Sport Psychologist, 1(3), 181 - 199.

[39]. M.Levêque,(2008). Psychologie de l'athlète. Radioscopie d'une carrière d'athlète de haut-niveau, Vuibert, Paris.

[40]. M.Levêque, (2010). Au cœur de la compétition. Approches psychologique et sociale, Mardaga, Bruxelles.

[41]. M.Levêque, (2012), L'athlète et son corps. In Psychologie du sport et de la santé. Sous la direction de G. Decamps, Editions De Boeck, pp 165-172.

[42]. M.Stevenson, (1999).The use of mental skills by male and female athletes: UMI, Ann Arbor, Mich.

[43]. N. Durand-Bush, J. H. Salmela\&I. Green-Demers, (2001). The Ottawa Mental Skills Assessment Tool (OMSAT-3*). The Sport Psychologist, 15, 1-19.

[44]. P. F.Ama, J. A. Simoneau, M. R. Boulay, O. Seresse, G. Thériault\& C. Bouchard, (1986). Skeletal muscle characteristics in sedentary black and Caucasian males. J ApplPhysiol 61: 1758-1761.

[45]. P. S. Freedson, P. Mihevic, A. Loucks\& R. Girandola, (1983). Physique body composition and psychological characteristics of competitive female body bulders, The physicians and sports medicine ,11, 85-90,93.

[46]. P.Quinn\& L.S.Liben, (2008).A sex difference in mental rotation in young infants. Psychological Science, 19, 1067-1070.

[47]. P.R.Thomas, S.M. Murphy\& L. Hardy, (1999), Test of performance strategies: Development and preliminary validation of acomprehensive measure of athletes, psychological skills, Journal of Sports Sciences, 1999, n 17, pp. 697-711

[48]. P.Therme, (2006). De l'incontournable prise en compte des émotions en EPS, Cahiers du CEDRE $\mathrm{n}^{\circ} 5$.

[49]. R. Neil, S.D. Mellalieu\& S. Hanton, (2004), Competitive anxiety and coping responses as a function of competitive status and experience. Journal of Sports Sciences 22, 309.

[50]. R.C.Thelwell, B.A. Such, N.J.V. Weston, J.D. Such\& I.A.Greenlees, (2010). Developing mental toughness: Perceptions of elite female gymnasts. International Journal of Sport and Exercise Psychology, 8, 170-188.

[51]. R.C.Thelwell, I.A. Greenlees\& N. Weston, (2006).Using psychological skills training to develop soccer performance. Journal of Applied Sport Psychology, 18, 254-270.

[52]. R.Neil, S.D. Mellalieu\& S. Hanton, (2006).Psychological skills usage and the competitive anxiety response as a function of skill level in rugby union. Journal of Sports Scienceand Medecine, 5, 415-423. 
[53]. R.Roure, C. Collet, C. Deschaumes-Molinaro, G.Delhomme, A. Dittmar\& E. Vernet-Maury, (1999). Imagery quality estimated by autonomic response is correlated to sporting performance enhancement. Physiology and Behavior, 66(1), 63-72.

[54]. R.Thad, S. Leffingwell, P. Rider\& J.M. Williams, (2001). Application of the transtheorical model to psychological skills training. The Sport Psychologist, 15, iss.2.

[55]. S.D.Mellalieu, R. Neil\& S. Hanton, (2006). An investigation of the mediating effects of self confidence between anxiety intensity and direction. Research Quarterly for Sport and Exercise 77, 263-270

[56]. S.D.Mellalieu, S. Hanton\& M. O’Brien, (2004).Intensity and direction of competitive anxiety as a function of sport type and experience. Scandinavian Journal of Science and Medicine inSport 14, 326-334.

[57]. T.Orlick, (2008), In Pursuit of Excellence: How to Win in Sport and Life through Mental Training. 4th Edition

[58]. T.Orlick\& J.Partington, (1986).Psyched: Inner views of winning, Ottawa: Coaching Association of Canada.

[59]. T.Orlick\& J.Partington, (1987).The sport psychology consultant: Analysis of critical components as viewed by Canadian Olympic athletes, The Sport Psychologist, 1, 4-17.

[60]. V. D. Heever, Z. H. Grobbelaar\& J. Potgieter, (2007). A survey of psychological skills training in South African netball: sport psychology, African Journal for Physical Health Education, Recreation and Dance, 13(3): 254-266.

[61]. Y. Theodorakis,R.S. Weinberg, P. Natis, I.Douma\& P.Kazakas, (2000).The Effects of Motivational Versus Instructional Self-Talk on Improving Motor Performance, The Sport Psychologist, Volume 14, Issue 3, September

[62]. Z.Li-Wei, M. Qi-Wei, T. Orlick\& L. Zitzelsberger, (1992). The effect of mental-imagery training on performance enhancement with 7-10-year-old children, The Sport Psychologist, 6 (3), 230-241. 